\section{Successful ERCP in a patient with situs inversus}

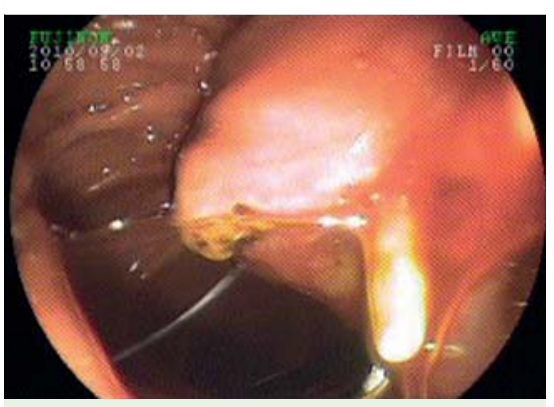

Fig. 1 Endoscopic view showing the papilla oriented to the right side, at the 3 o'clock position.

Situs inversus viscerum is a rare condition in which the organs are transposed to the opposite side [1]. Endoscopic procedures can be difficult in patients with situs inversus because of the left-right reversal of the visceral organs. We present a patient with choledocholithiasis who had situs inversus. Endoscopic retrograde cholangiopancreatography (ERCP) was performed with minor modification of maneuvers with the patient lying in the usual left lateral decubitus position.

A 60-year-old woman was admitted to our clinic with abdominal pain at the left upper quadrant, jaundice, and fever. Ab- dominal ultrasound showed transposition of the liver and bile ducts to the left upper quadrant, and a dilated common bile duct containing a stone measuring $1 \mathrm{~cm}$ in diameter. ERCP was performed and revealed distortion of the gastric anatomy, with an inverted location of the greater and lesser curves. The papilla was oriented to the right side, at the 3 o'clock position ( Fig. 1). The papilla and common bile duct were cannulated by rotating the sphincterotome tip and manipulating the guidewire toward the right side. ERCP showed transposition of the gallbladder and bile ducts to the left side and the pancreatic duct to right side ( $\bullet$ Fig. 2 ). Biliary sphincterotomy was performed using the same sphincterotome (Autotome Rx 49; Boston Scientific Co., Natick, Massachusetts, USA) in the 12 o'clock position, and purulent bile and a stone were removed. Transposition of the abdominal viscera associated with situs inversus requires technical changes to the ERCP procedure [2]. In this situation, different techniques, such as the "mirror image" technique [3], may be needed for cannulation of the papilla. Alternatively ERCP can be performed in the usual prone position but there may be technical difficulties [4].

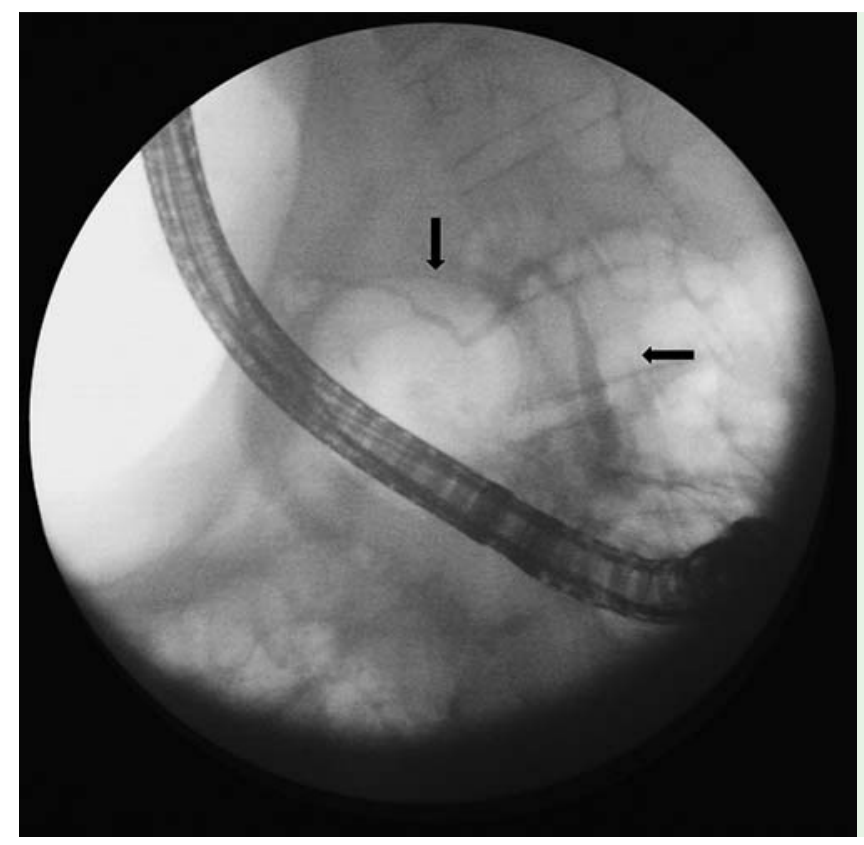

Fig. 2 Endoscopic retrograde cholangiopancreatography (ERCP) showing the pancreatic duct lying to right side.
In this case, we were able to carry out the ERCP with the patient in the usual left lateral decubitus position; however, a rotatable sphincterotome was required because of the ectopic location of the papilla. In spite of this anatomical variation, it was possible to complete the intended procedure, demonstrating that ERCP can be performed safely in patients with situs inversus.

\section{Endoscopy_UCTN_Code_TTT_1AR_2AC}

\section{Competing interests: None}

\section{Şahin Çoban ${ }^{1}$, Ilhami Yüksel ${ }^{1,2}$, Metin Küçülkazman ${ }^{3}$, Ömer Başar ${ }^{1}$}

${ }^{1}$ Department of Gastroenterology, Dışkapı Yıldırım Beyazıt Education and Research Hospital, Ankara, Turkey

${ }^{2}$ Department of Gastroenterology, School of Medicine, Yildirim Beyazit University, Ankara, Turkey

${ }^{3}$ Department of Gastroenterology, Kecioren Education and Research Hospital, Ankara, Turkey

\section{References}

1 Casey B. Genetics of human situs abnormalities. Am J Med Genet 2001; 101: 356-358

2 Cheon YK, Fogel EL. ERCP topics. Endoscopy 2006; 38: $1092-1097$

3 García-Fernández FJ, Infantes JM, Torres Y et al. ERCP in complete situs inversus viscerum using a "mirror image" technique. Endoscopy 2010; 42 (Suppl. 02): E316-E317

4 de la Serna-Higuera C, Perez-Miranda M, Flores-Cruz $G$ et al. Endoscopic retrograde cholangiopancreatography in situs inversus partialis. Endoscopy 2010; 42 (Suppl. 02): E98

\section{Bibliography}

Dol http://dx.doi.org/

10.1055/s-0034-1365289

Endoscopy 2014; 46: E222

c) Georg Thieme Verlag KG

Stuttgart · New York

ISSN 0013-726X

\section{Corresponding author}

\section{Şahin Çoban, MD}

Çukurambar Mah. Ogretmenler Cd. 23/15

Çankaya

Ankara, 06520

Turkey

Fax: +90-312-3186690

scoban72@yahoo.com 